\title{
Disinhibition is easier learned than inhibition. The effects of (dis)inhibition training on food intake
}

Citation for published version (APA):

Guerrieri, R., Nederkoorn, C., \& Jansen, A. (2012). Disinhibition is easier learned than inhibition. The effects of (dis)inhibition training on food intake. Appetite, 59(1), 96-9.

https://doi.org/10.1016/j.appet.2012.04.006

Document status and date:

Published: 01/01/2012

DOI:

10.1016/j.appet.2012.04.006

Document Version:

Publisher's PDF, also known as Version of record

Document license:

Taverne

Please check the document version of this publication:

- A submitted manuscript is the version of the article upon submission and before peer-review. There can be important differences between the submitted version and the official published version of record.

People interested in the research are advised to contact the author for the final version of the publication, or visit the DOI to the publisher's website.

- The final author version and the galley proof are versions of the publication after peer review.

- The final published version features the final layout of the paper including the volume, issue and page numbers.

Link to publication

\footnotetext{
General rights rights.

- You may freely distribute the URL identifying the publication in the public portal. please follow below link for the End User Agreement:

www.umlib.nl/taverne-license

Take down policy

If you believe that this document breaches copyright please contact us at:

repository@maastrichtuniversity.nl

providing details and we will investigate your claim.
}

Copyright and moral rights for the publications made accessible in the public portal are retained by the authors and/or other copyright owners and it is a condition of accessing publications that users recognise and abide by the legal requirements associated with these

- Users may download and print one copy of any publication from the public portal for the purpose of private study or research.

- You may not further distribute the material or use it for any profit-making activity or commercial gain

If the publication is distributed under the terms of Article $25 \mathrm{fa}$ of the Dutch Copyright Act, indicated by the "Taverne" license above, 
Research report

\title{
Disinhibition is easier learned than inhibition. The effects of (dis)inhibition training on food intake
}

\author{
Ramona Guerrieri* , Chantal Nederkoorn, Anita Jansen \\ Department of Clinical Psychological Science, Maastricht University, P.O. Box 616, 6200 MD Maastricht, The Netherlands
}

\section{A R T I C L E I N F O}

\section{Article history:}

Received 9 November 2011

Received in revised form 28 March 2012

Accepted 10 April 2012

Available online 17 April 2012

\section{Keywords:}

Impulsivity

Inhibition

Response inhibition

Stop signal task

Obesity

Overeating

\begin{abstract}
A B S T R A C T
Impulsivity seems to be a strong candidate when it comes to psychological factors leading to overeating and eventually to obesity (Guerrieri, Nederkoorn, \& Jansen, 2008). The question is whether reversing the logic and strengthening an individual's inhibitory skills will be equally potent against overeating. In the current study the stop signal task was adjusted so that one group of female students $(n=21)$ gradually got more trials in which they could practise inhibition (inhibition), whereas another group $(n=20)$ gradually got more trials in which they had to react quickly, without having time to think or inhibit (impulsivity). A third group $(n=20)$ did a neutral reading task (control). The participants in the impulsivity group had a significantly higher caloric intake during a subsequent taste test, whereas the inhibition group did not differ from the control group. Hence, the data support that impulsivity is a direct cause of overeating. However, the concept of inhibition training needs to be investigated further. Issues like the specificity of inhibition training (general vs. food specific) need to be addressed and used to optimise the training so that its effectiveness can be tested within clinical settings.
\end{abstract}

(c) 2012 Elsevier Ltd. All rights reserved.

\section{Introduction}

Weight problems have become a hot topic when it comes to public health. Weight status is generally assessed by the Body Mass Index (BMI), calculated by dividing one's weight $(\mathrm{kg})$ by one's height $(\mathrm{m})$ squared. A BMI between 18.5 and 24.9 constitutes a normal weight, whereas a BMI ranging from 25 to 29.9 is defined as overweight and a BMI of 30 or more as obesity. The last decades have been hallmarked by a significant increase of overweight and obesity among children and adults (Bassett, Pucher, Buehler, Thompson, \& Crouter, 2008; Ogden et al., 2006). In the United States for example $65 \%$ of the population is overweight or obese (Hedley et al., 2004).

Finding out how obesity is caused is of paramount importance because it will help us to stop this epidemic and hence its unfavourable health, psychological and social outcomes (Hu, 2003; Karlsson, Taft, Sjöström, Torgerson, \& Sullivan, 2003).

Answering the question how obesity arises is not simple. There seems to be an intricate interplay between all sorts of factors: genetic, biological, psychological, environmental and sociocultural (Drewnowski, 1991; Hill \& Peters, 1998; Lowe, 2003). However, before looking into interactions between causal factors, it is important that they are identified and investigated in their own right.

\footnotetext{
* Corresponding author.

E-mail address: r.guerrieri@maastrichtuniversity.nl (R. Guerrieri).
}

Based on previous research impulsivity seems to be a strong potential psychological factor (Guerrieri, Nederkoorn, \& Jansen, 2008). Generally, impulsivity is defined as the tendency to think, control and plan insufficiently, resulting in an inaccurate or maladaptive response (Solanto et al., 2001). Impulsive behaviours are very diverse and include for example, sensitivity to reward and insufficient prepotent response inhibition (Guerrieri et al., 2008). In this study impulsivity was operationalised as insufficient response inhibition. Nederkoorn and colleagues were the first to link insufficient response inhibition to obesity. They found that obese children were impaired in general response inhibition, and thus impulsive, compared to control participants (Nederkoorn, Braet, Van Eijs, Tanghe, \& Jansen, 2006). In other words, even on a very basic motor level that has nothing to do with food the obese children were less able to inhibit their responses. Moreover, impulsivity turned out to be an obstacle in the treatment of the obese children: the children that were worst at inhibiting responses, lost less weight (Nederkoorn et al., 2006; Nederkoorn, Jansen, Mulkens, \& Jansen, 2007). The question remained whether impulsivity directly causes overeating. As a first step the link between impulsivity and overeating was investigated within a group of healthy normal-weight women. Indeed, high impulsive women overate in the lab compared to low impulsive women, although they had a healthy weight (Guerrieri, Nederkoorn, \& Jansen, 2007). As hypothesised, later experimental studies indicated that impulsivity causes overeating (Guerrieri, Nederkoorn, Schrooten, Martijn, \& Jansen, 2009; Guerrieri, Nederkoorn, Stankiewicz, et al., 2007). In one 
study, for example, manipulating impulsivity vs. inhibition led to a higher intake of the impulsivity group in the lab compared to the inhibition group, at least for non-dieters (Guerrieri et al., 2009).

If inducing impulsive behaviour causes overeating, it could well be that training inhibition could actually protect against overeating. This has already been shown for inhibition training tasks that specifically focus on palatable food stimuli (Houben, 2011; Houben \& Jansen, 2011; Veling, Aarts, \& Papies, 2011; Veling, Aarts, \& Stroebe, 2011). The study of Guerrieri et al. (2009) and the current study differ from these studies in the sense that general response inhibition skills are tackled, with the expectation that the improvement in inhibition will transfer to eating behaviour when individuals are put in a tempting food situation. This is much like general working memory trainings result in the reduction of very specific behaviours such as inattentive symptoms in children with Attention Deficit Hyperactivity Disorder (ADHD; Klingberg et al., 2005).

The results of the previous study of Guerrieri and colleagues (2009) could not be interpreted fully. There were two groups; inhibition was manipulated vs. inhibition. This only gave the opportunity to compare the mean food intake in the inhibition group with that of the impulsivity group. However, without a neutral control group, a difference in caloric intake between the inhibition and impulsivity group could be due to three different processes. There could be less intake in the inhibition group (a successful inhibition manipulation), more intake in the impulsivity group (a successful impulsivity manipulation), or a combination of both (both manipulations were successful). In other words, in order to find out whether inhibition training has any clinical relevance, we need to manipulate inhibition and compare acute caloric intake after the manipulation with intake in a neutral control group.

In sum, the current study aims not only to induce impulsivity, which is theoretically interesting in the sense that it demonstrates that impulsivity is a direct cause of overeating. If we can induce inhibition and if this induced inhibition leads to less food intake in the lab compared to the neutral control group and the impulsivity group, training inhibition becomes an option that might be clinically relevant. In other words, the hypotheses of this study are twofold. First, we expected that training participants by having them inhibit responses should lead to less caloric intake during a subsequent taste test. Second, training participants to react quickly without forethought should lead to more caloric food intake during a subsequent taste test.

\section{Methods}

\section{Participants}

Sixty-one normal-weight female undergraduate students (age: 21.43 years \pm 2.12 ; BMI: $22.20 \pm 2.78$ ) were recruited to participate in a study on taste perception. Participants were randomly allocated to one of three conditions: impulsivity (20), inhibition (21), or neutral control (20). All participants were tested individually and received course credit in exchange for their participation. None of the participants was aware of the hypotheses of the study, hence the data of all participants were included in the analyses. The procedure of the study was approved by the Ethical Committee of Maastricht University.

\section{Materials}

The stop signal task (SST; Logan, Schachar, \& Tannock, 1997) is a behavioural task that is normally used to measure impulsive behaviour in the form of insufficient response inhibition. In this study the stop signal task served as a way to induce impulsivity vs. inhibition. The classic version of the SST consists of two sorts of trials. In $75 \%$ of the trials participants are asked to push a button as quickly as possible in response to a stimulus (go trials). In $25 \%$ of the trials it is the participants' task to inhibit this response when they hear a tone that serves as a stop signal (stop trials). It was our intention to gradually provide the participants with more practice in stop trials (inhibition group) or go trials (impulsivity group) by changing the proportion of stop vs. go trials. The task consisted of six blocks of 100 trials each. Both groups started out with a block of 100 trials of the classic stop signal task that consists of 25\% stop trials and $75 \%$ go trials. In the inhibition group the proportion of stop trials rose with $5 \%$ in each consecutive block. In block 6 the proportion of stop trials had risen to $50 \%$. In the impulsivity group the proportion of go trials rose with $5 \%$ in each consecutive block until the proportion of go trials was $100 \%$ in the last block. In the inhibition group the gradual rise of the proportion of stop trials from $25 \%$ to $50 \%$ should focus the participants on their control behaviour, and should give them the chance to practise inhibition at the same time. The opposite is true for the impulsivity group. The participants in this group are focused on reacting quickly, while they gradually get more and more chance to practise this (75\% of the trials in block 1 and 100\% in block 6). We reasoned that during the food intake the participants would probably persist in the behaviour that they had focused on and trained during the experimental task. It might seem more effective to have participants react or inhibit as much as possible (100\% during the last block). This is possible for the impulsivity group, in which there is no objection against participants inhibiting $100 \%$ of the time during the last block. However, for the inhibition group this is problematic. The stop signal task measures prepotent response inhibition. This means that inhibition in the task depends on the availability of a dominant go-response. If one would present stop signals in more than $50 \%$ of the trials, the go-response would cease to play that role. Without a dominant response to inhibit, inhibition cannot be trained. Moreover, an added advantage is that, in comparison to the original stop signal task ( $75 \%$ go vs. $25 \%$ stop), in both the impulsivity and inhibition groups get an equal amount of extra practice (25\%) in go or stop-trials, respectively.

The participants who were assigned to the control group were asked to read two neutral stories about hearing aids and a nature phenomenon named 'gamma flash' with the instruction to make a summary of each text after reading. Moreover, they had to review their summaries critically and assess which one was the best and why. It was made sure that the control task took an equal amount of time. All three tasks were tested by seven students who estimated that the tasks take up a comparable amount of cognitive capacity.

A Bogus Taste Test was used in order to measure food intake of the participants in an unobtrusive way. Participants were left alone for 15 min to taste and rate four sorts of food that were placed in front of them in large bowls: mini chocolate chip cookies (486 kcal/100 g), wine gums (330 kcal/100 g), paprika-flavoured crisps (550 kcal/100 g) and saltines (442 kcal/100 g). Participants had to rate odour, general palatability and, depending on the sort of food, sweetness, creaminess, saltiness and crunchiness. However, the primary interest of the authors was not how participants rated the taste of the food, but how much they ingested of the food that was offered. Without the participants' knowledge the bowls of food were weighed before and after the taste test in order to establish food intake. The amounts eaten of each food were converted to calories. The sum of these calories was the dependent variable: total caloric intake.

\section{Procedure}

At recruitment participants were asked to eat something small like a cheese sandwich $2 \mathrm{~h}$ before the start of the experiment and 
to otherwise refrain from eating and drinking (except water). This was done in order to control for differing states of hunger between the conditions at the start of the experiment.

At their arrival in the lab, participants' hunger was measured. However, in order not to prime participants with the concept of hunger or make them especially aware of their hunger feelings, a VAS item checking the participants' hunger was embedded in a "health questionnaire" which also contained items on smoking and drinking habits, and their ability to concentrate. Before starting with the taste test, participants were randomly assigned to the inhibition, neutral or impulsivity group and received one of the three tasks. Afterwards participants did the taste test, which lasted $15 \mathrm{~min}$. After the taste test the participants received another short questionnaire checking whether they had adhered to the instructions before coming to the lab, and checking whether participants had any relevant knowledge concerning the precise aims of the study. Participants were weighed and measured without shoes and heavy clothing. At the end of the experiment, the participants were thanked and dismissed. They were debriefed by e-mail after all the participants had been tested.

\section{Results}

Pre-existing differences between the inhibition, neutral and impulsivity group

It was checked whether the inhibition, impulsivity and neutral group differed beforehand on hunger and BMI (see Table 1 for means and standard errors per group). For this purpose two oneway ANOVA's were conducted. The three groups did not differ significantly on hunger $(F(2,58)=0.30 ; p>0.9)$, nor on BMI $(F(2,58)=0.39 ; p>0.6)$.

\section{Effect of inhibition/impulsivity task on caloric intake}

A one-way ANOVA was conducted to check for differences in caloric intake between the inhibition, neutral and impulsivity group. The groups differed significantly in caloric intake $(F(2,58)$ $=3.80 ; p<0.03$, partial $\eta^{2}=0.12$ ). Pairwise comparisons indicated that caloric intake in the impulsivity group was significantly higher compared to the neutral group $\left(p<0.05\right.$, partial $\left.\eta^{2}=0.12\right)$ and to the inhibition group $\left(p<0.05\right.$, partial $\left.\eta^{2}=0.08\right)$. Caloric intake in the inhibition group did not differ significantly from that in the neutral group $\left(p>0.30\right.$, partial $\left.\eta^{2}=0.02\right)$. See Fig. 1 for means and standard errors.

\section{Discussion}

The aim of this study was twofold. First, we attempted to replicate the finding that impulsivity is causally linked to overeating by manipulating impulsivity. Second, we tested whether an inhibition training would decrease subsequent food intake. For this purpose

Table 1

Means (M) and standard errors (SE) of hunger at the start of the experiment and BMI per group.

\begin{tabular}{llll}
\hline & $n$ & $\mathrm{M}$ & $\mathrm{SE}$ \\
\hline Hunger (0-100) & & & \\
Inhibition group & 21 & 49.67 & 5.11 \\
Neutral group & 20 & 53.00 & 6.33 \\
Impulsivity group & 20 & 51.50 & 5.04 \\
BMI & & & \\
Inhibition group & 21 & 22.64 & 0.69 \\
Neutral group & 20 & 21.94 & 0.50 \\
Impulsivity group & 20 & 22.00 & 0.65 \\
\hline
\end{tabular}

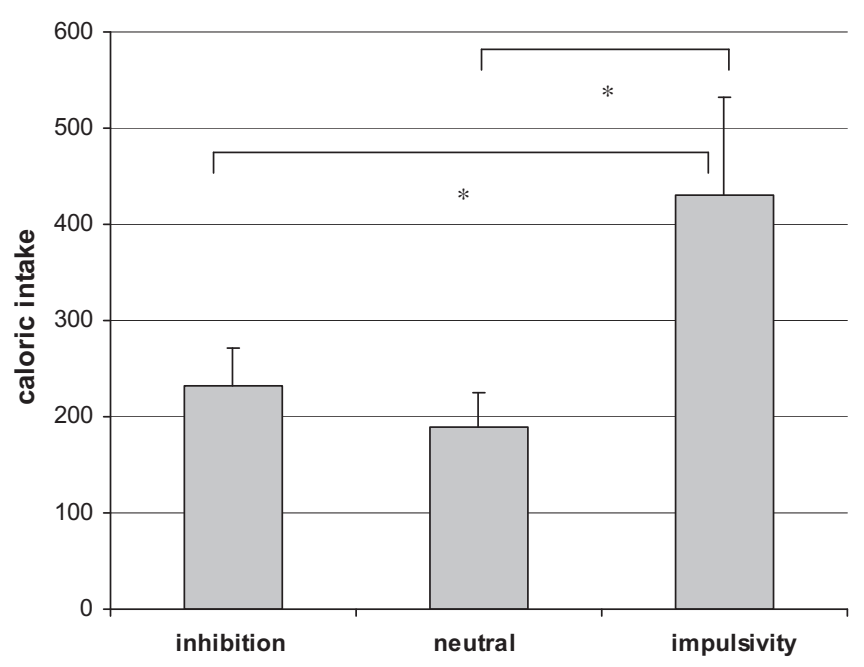

Fig. 1. Mean caloric intake and standard error per group $\left({ }^{*} p \leqslant 0.05\right)$.

participants performed one of two stop-signal tasks. In the impulsivity group the proportion of go trials gradually increased with each block, whereas this was the case for the proportion of stop trials in the inhibition group. A neutral group, performing a reading task, was included as a baseline. It was hypothesised that caloric intake would differ between groups. The impulsivity group was hypothesised to have the highest caloric intake, followed by the neutral group, which was expected to have a significantly higher caloric intake compared to the inhibition group.

The hypotheses were partly confirmed. As predicted, the impulsivity group had a significantly higher intake compared to the neutral group and the inhibition group. However, caloric intake in the inhibition group did not differ significantly from that in the neutral group.

In other words, we confirmed once again that impulsivity indeed causes overeating: a group of participants, randomly assigned to a group undergoing a manipulation that is considered to make them impulsive, overeat in the lab compared to participants in the neutral and inhibition group. However, the clinically relevant option of training inhibition in order to provide individuals with a tool against overeating was not successful.

Why would the manipulation of impulsivity successfully affect caloric intake, whereas manipulating inhibition has no effect? There seem to be two options. First, it is theoretically possible that inhibition and impulsivity are rather separate behavioural dimensions, and not two extremes of a continuum. Impulsivity is a very broad concept, and in some cases it might indeed be that impulsivity is not necessarily the exact opposite of inhibition. Impulsivity might, for instance, be operationalised as not having sufficient sustained attention to accomplish a goal or task, but lacking sufficient planning abilities to attain that goal is just as much seen as a manifestation of impulsivity (e.g. Patton, Stanford, \& Barratt, 1995). One can imagine that behaviours having to do with both planning abilities and sustained attention are not exact opposites of inhibition behaviour. However, in this study impulsivity was operationalised as having insufficient response inhibition. Impulsivity and inhibition are so much intertwined in this case, that it is highly likely that they represent two extremes of one behavioural continuum. This leaves us with the second option: inhibition training has the potential to work, but for some practical or methodological reason it does not.

We can think of four sorts of reasons. First, we could be dealing with a ceiling effect in the case of this particular study. Our participants are assumed to be healthy normal-weight university 
students who are expected to have quite good inhibition skills to begin with, leaving little room for improvement. This could be especially true in an artificial laboratory context. Unfortunately, we do not have any baseline measurements of the participants' inhibition skills, which makes it impossible to test this assumption. Moreover, we cannot rule out that some participants might have struggled with some form of eating pathology since we did not measure this. However, it might be more effective to test an inhibition training in a group that is known to have inhibition problems to begin with, such as highly restrained participants (Jansen et al., 2009) or obese participants (Nederkoorn et al., 2006). Second, it is possible that the neutral task that was used in this study was not neutral. It was assumed that reading and summarising a text would not train inhibitory or disinhibitory skills. However, this was not tested. The standard version of the stop signal task $(75 \%$ go trials vs. $25 \%$ stop trials) was not chosen as a neutral task because previous research (Guerrieri et al., 2009) has shown that this task can influence eating behaviour in different ways dependent on the mind set that participants are in. Since we cannot control these kinds of variables, the reading task was seen as a better option. Third, it could be the case that inhibition is generally harder to train compared with impulsivity, which means that in order to get the same effect, an inhibition manipulation must be stronger compared to an impulsivity manipulation. In this study both manipulations were equal in the sense that in both groups the respective trials to be practised with $5 \%$ in each consecutive block. This would be comparable to the problem found in mood inductions: the same method used to induce a negative mood is less effective when used to induce a positive mood (Westermann, Spies, Stahl, \& Hesse, 1996). Although research links general response inhibition abilities to specific eating behaviour (e.g. Guerrieri, Nederkoorn, \& Jansen, 2007; Nederkoorn et al., 2006), a fourth option is that the training of general inhibitory skills is not strong enough to illicit an effect at the level of eating behaviour. In other words, it might be possible that inhibition training should be focused specifically on food, or even on specific types of food before an effect on caloric intake can be expected. Houben and Jansen (2011) did just that. They targeted high vs. low chocolate cravers and trained them by having them consistently react to chocolate stimuli (impulsivity), consistently not react (inhibition), or react half of the time (control). Indeed, the inhibition group ate significantly less compared to the other two groups, whereas caloric intake in the impulsivity and control condition did not differ. It is thus possible that inhibition training needs to be tuned to a specific behaviour or stimulus. However, it could also be the case that specific inhibition training simply has the benefit of allowing the selection of high cravers of that specific food, ruling out ceiling effects.

In summary, it is clear that impulsivity is one of the causes of overeating. However, more research is needed to find how inhibition can be trained and which form of inhibition training has the most potential.

\section{References}

Bassett, D. R., Jr., Pucher, J., Buehler, R., Thompson, D. L., \& Crouter, S. E. (2008). Walking, cycling, and obesity rates in Europe, North America, and Australia. Journal of Physical Activity and Health, 5(6), 795-814.

Drewnowski, A. (1991). Obesity and eating disorders. Cognitive aspects of food preference and food aversion. Bulletin of the Psychonomic Society, 29, 261-264.

Guerrieri, R., Nederkoorn, C., \& Jansen, A. (2007). How impulsiveness and variety influence food intake in a sample of healthy women. Appetite, 48, 119-122.

Guerrieri, R., Nederkoorn, C., \& Jansen, A. (2008). The effect of an impulsive personality on overeating and obesity. Current state of affairs. Psychological Topics, 17, 265-286.

Guerrieri, R., Nederkoorn, C., Schrooten, M., Martijn, C., \& Jansen, A. (2009). Inducing impulsivity leads high and low restrained eaters into overeating, whereas current dieters stick to their diet. Appetite, 53, 93-100.

Guerrieri, R., Nederkoorn, C., Stankiewicz, K., Alberts, H., Geschwind, N., Martijn, C., et al. (2007). The influence of trait and induced state impulsivity on food intake in normal-weight healthy women. Appetite, 49, 66-73.

Jansen, A., Nederkoorn, C., van Baak, L., Keirse, C., Guerrieri, R., \& Havermans, R. . Behaviour Research and Therapy, 47, 105-110.

Hedley, A. A., Ogden, C. L., Johnson, C. L., Carroll, M. D., Curtin, L. R., \& Flegal, K. M. (2004). Prevalence of overweight and obesity among US children, adolescents, and adults, 1999-2002. Journal of the American Medical Association, 291, 2847-2850.

Hill, J. O., \& Peters, J. C. (1998). Environmental contributions to the obesity epidemic. Science, 280, 1371-1374.

Houben, K. (2011). Overcoming the urge to splurge. Influencing eating behavior by manipulating inhibitory control. Journal of Behavior Therapy and Experimental Psychiatry, 42, 384-388.

Houben, K., \& Jansen, A. (2011). Training inhibitory control. A recipe for resisting sweet temptations. Appetite, 56, 345-349.

Hu, F. B. (2003). Overweight and obesity in women. Health risks and consequences. Journal of Women's Health, 12, 163-172.

Klingberg, T., Fernell, E., Olesen, P. J., Johnson, M., Gustafsson, P., Dahlström, K., et al. (2005). Computerized training of working memory in children with ADHD-A randomized, controlled trial. Journal of the American Academy of Child and Adolescent Psychiatry, 44, 177-186.

Logan, G. D., Schachar, R., \& Tannock, R. (1997). Impulsivity and inhibitory control. Psychological Science, 8, 60-64.

Lowe, M. R. (2003). Self-regulation of energy intake in the prevention and treatment of obesity. Is it feasible? Obesity Research, 11, 44S-59S.

Karlsson, J., Taft, C., Sjöström, L., Torgerson, J. S., \& Sullivan, M. (2003). Psychosocial functioning in the obese before and after weight reduction. Construct validity and responsiveness of the Obesity-related Problems scale. International Journal of Obesity, 27, 617-630.

Nederkoorn, C., Braet, C., Van Eijs, Y., Tanghe, A., \& Jansen, A. (2006). Why obese children cannot resist food. The role of impulsivity. Eating Behaviors, 7, 315-322.

Nederkoorn, C., Jansen, E., Mulkens, S., \& Jansen, A. (2007). Impulsivity predicts treatment outcome in obese children. Behaviour Research and Therapy, 45, 1071-1075

Ogden, C. L., Carroll, M. D., Curtin, L. R., McDowell, M. A., Tabak, C. J., \& Flegal, K. M. (2006). Prevalence of Overweight and Obesity in the United States, 1999-2004. JAMA: Journal of the American Medical Association, 295(13), 1549-1555.

Patton, J. H., Stanford, M. S., \& Barratt, E. S. (1995). Factor structure of the Barratt Impulsiveness Scale. Journal of Clinical Psychology, 51, 768-774.

Solanto, M. V., Abikoff, H., Sonuga-Barke, E., Schachar, R., Logan, G. D., Wigal, T., et al. (2001). The ecological validity of delay aversion and response inhibition as measures of impulsivity in $\mathrm{AD} / \mathrm{HD}$. A supplement to the NIHM multimodal treatment study of AD/HD. Journal of Abnormal Child Psychology, 29, 215-228.

Veling, H., Aarts, H., \& Stroebe, W. (2011). Fear signals inhibit impulsive behavior toward rewarding food objects. Appetite, 56(3), 643-648.

Veling, H., Aarts, H., \& Papies, E. K. (2011). Using stop signals to inhibit chronic dieters' responses toward palatable foods. Behaviour Research and Therapy, 49, 771-780.

Westermann, R., Spies, K., Stahl, G. n., \& Hesse, F. W. (1996). Relative effectiveness and validity of mood induction procedures. A meta-analysis. European Journal of Social Psychology, 26(4), 557-580. 